\title{
LOS BUQUES DE LA OPERACIÓN SOPHIA EN EL DIQUE SECO: ELEMENTOS DE UN REVÉS PARA LA POLÍTICA COMÚN DE SEGURIDAD Y DEFENSA \\ CARLOS ESPALIÚ BERDUD ${ }^{1}$ \\ cespaliu@nebrija.es
}

Cómo citar/Citation

Espaliú Berdud, C. (2019).

Los buques de la operación Sophia en el dique seco: elementos de un revés para la Política Común de Seguridad y Defensa. Revista de Derecho Comunitario Europeo, 64, 829-858. doi: https://doi.org/10.18042/cepc/rdce.64.02

\section{Resumen}

La operación Sophia de la UE, que se estableció en 2015 para luchar contra el negocio del tráfico y la trata de personas en el Mediterráneo, se encuentra en una situación de parálisis, pues se ha decidido retirar los buques de la misma y, prácticamente, solo tiene como cometido el adiestramiento de las fuerzas de guardacosta libias para que sean ellas las que luchen contra aquellos crímenes. En este artículo hemos repasado los resultados que ha producido hasta el momento la operación naval de la UE y las causas de que se encuentre en la situación actual, para determinar si se puede decir o no que ha fracasado. A la luz de nuestra investigación, hemos llegado a la conclusión de que sí se puede afirmar que no ha respondido a las expectativas que se crearon cuando nació. No obstante, en honor de la verdad, pensamos que el fiasco de Sophia, en realidad, no es tanto un fracaso de la operación en sí misma como más bien una manifestación de los límites de la PCSD.

\section{Palabras clave}

PCSD; operación Sophia; crisis migratoria; tráfico de migrantes; trata de personas; Unión Europea; Libia; Italia.

1 Catedrático de Derecho Internacional Público y de la Unión Europea. Secretario General en funciones. Investigador principal del Grupo en Seguridad, Gestión de Riesgos y Conflictos, Universidad Nebrija. 


\title{
THE SHIPS OF OPERATION SOPHIA IN THE DRY DOCK: ELEMENTS OF A SETBACK FOR THE COMMON SECURITY AND DEFENCE POLICY
}

\begin{abstract}
Operation Sophia of the EU, which was established in 2015 to fight against the migrant smuggling and trafficking in persons business in the Mediterranean, is in a state of paralysis, as it has been decided to withdraw the ships from the sea. Thus, it has only the task of training the Libyan coastguard forces so that they are the ones who persecute those crimes. In this article, we have reviewed the results that the EU naval operation has produced so far and the causes of its current situation, to determine whether or not it can be said that it has failed. All in view, we have come to the conclusion that yes it can be said that it has not responded to the expectations that were raised in its inception. However, in honor of the truth, we think that Sophia's paralysis, in reality, is not so much a failure of the operation itself, but rather expresses the limits of the PCSD.
\end{abstract}

\section{Keywords}

CSDP; operation Sophia; migratory crisis; smuggling of migrants; trafficking in persons; European Union; Libya; Italy.

\section{LES NAVIRES DE L'OPÉRATION SOPHIA NE NAVIGUENT PAS: LES ÉLÉMENTS D'UN REVERS DE LA POLITIQUE DE SÉCURITÉ ET DE DÉFENSE COMMUNE}

\section{Résumé}

L'opération Sophia de l'UE, créée en 2015 pour lutter contre le trafic et la traite des êtres humains en Méditerranée, est dans un état de paralysie car il a été décidé de retirer les navires de la mer et, pratiquement, elle n'a pour tâche que de former les forces de garde-côtes libyennes pour qu'elles luttent contre ces crimes. Dans cet article, nous avons passé en revue les résultats obtenus jusqu'ici par l'opération navale de l'Union européenne et les causes de sa situation actuelle, afin de déterminer si l'on peut ou non dire qu'elle a échoué. Nous sommes arrivés à la conclusion que oui, on peut dire qu'il n'a pas répondu aux attentes qui ont été créées lors de sa naissance. Cependant, en l'honneur de la vérité, nous pensons que le revers de Sophia n'est en réalité pas un échec de l'opération elle-même, mais qu'il exprime plutôt les limites de la PSDC.

\section{Mots clés}

PSDC; opération Sophia; crise migratoire; trafic de migrants; traite des personnes; Union européenne; Libye, Italie 


\section{SUMARIO}

I. INTRODUCCIÓN. II. LOS RESULTADOS DE LA OPERACIÓN SOPHIA HASTA EL MOMENTO. III. EL PAPEL DEL CONSEJO DE SEGURIDAD DE LAS NACIONES UNIDAS EN EL ENCALLAMIENTO ACTUAL DE LA OPERACIÓN SOPHIA. IV. EL PAPEL DE ITALIA EN LA DERIVA Y EN LA PARÁLISIS PRESENTE DE LA OPERACIÓN. V. EL PAPEL DE LA ACTUACIÓN DE LAS FUERZAS DE GUARDACOSTA LIBIAS EN LA HIBERNACIÓN DE LA OPERACIÓN NAVAL DE LA UNIÓN EUROPEA. VI. CONCLUSIONES. BIBLIOGRAFIA.

\section{INTRODUCCIÓN}

En los últimos años asistimos en Europa a una crisis migratoria de grandes dimensiones que ha tenido en el Mediterráneo su escenario más dramático, con miles de muertes de personas que trataban de llegar a nuestras costas en busca de un futuro más prometedor. El punto álgido de la crisis vino, quizá, constituido por el naufragio, el 18 de abril de 2015, frente a las costas de Libia, de un pesquero con más de ochocientas personas a bordo. Este hecho golpeó las conciencias de los responsables europeos de las diversas instituciones, órganos y agencias de la Unión Europea (UE), que comenzaron a reflexionar sobre cómo hacer frente a la crisis. Así, la Comisión Europea adoptó el 13 de mayo de 2015 la Agenda Europea de la Migración, en la que reclamaba una política europea común en materia de migración que aglutinara los esfuerzos de las instituciones de la UE, de los Estados miembros, de las autoridades locales, y que se realizara en conjunción con terceros países y otras organizaciones internacionales ${ }^{2}$.

Ese llamamiento no cayó en saco roto y en la UE se empezaron a realizar planes para llevar a cabo acciones en solitario o en conjunción con otras organizaciones internacionales o terceros Estados. De hecho, en ese instrumento ya se anunciaba que la alta representante de la UE para Asuntos Exteriores y Política de Seguridad había esbozado posibles operaciones en el ámbito de la Política Común de Seguridad y Defensa (PCSD), dirigidas a la identificación,

2 Comisión Europea, ««Una agenda europea de migración»», COM(2015) 240 final, 13 de mayo de 2015. 
captura y destrucción de las embarcaciones empleadas por los traficantes de personas ${ }^{3}$. A este respecto, debemos recordar que el Tratado de Lisboa había dado un fuerte impulso a la PCSD en general y en particular a las operaciones de gestión de crisis ${ }^{4}$. En relación con estas últimas, en el art. 42 (1) del Tratado de la Unión Europea se hace notar que la PCSD «[o]frecerá a la Unión una capacidad operativa basada en medios civiles y militares», que podrán ser usados «[...] en misiones fuera de la Unión que tengan por objetivo garantizar el mantenimiento de la paz, la prevención de conflictos y el fortalecimiento de la seguridad internacional, conforme a los principios de la Carta de las Naciones Unidas», con lo que se pretende dotar a la UE de las competencias necesarias para desarrollar un papel cada vez más relevante en la esfera mundial.

Pues bien, en este marco de la PCSD, el Consejo de la Unión Europea decidió, el 18 de mayo de 2015, poner en marcha una operación de gestión de crisis de tipo militar naval inicialmente denominada EUNAVFOR MED ${ }^{5}$, aunque posteriormente se rebautizó como Sophia, con objeto de frenar la migración ilegal hacía Europa por la vía del Mediterráneo central ${ }^{6}$.

Se entenderá mejor la elección de una operación militar para luchar contra la migración ilegal si se tiene en cuenta que la operación Sophia fue establecida en un momento en que se sentía una necesidad imperiosa de actuar con rapidez ante las proporciones de la tragedia que se vivía en toda la cuenca del Mediterráneo, y cuando los resultados positivos de la operación Atalanta eran ya evidentes a todos ${ }^{7}$. Se pensó que el lanzamiento de una operación naval de la UE era una buena medida, tanto para complementar la labor de

3 Ibid., p. 4.

4 Creando, además, una cláusula de asistencia mutua, una cláusula de solidaridad y previendo la creación de una cooperación estructurada permanente. Sobre la evolución histórica de la PCSD, véase, entre otras obras, Koutrakos (2013: 5-78). Sobre el presente y futuro de la misma, véase, entre otros trabajos, De Castro y Borrajo (2019: 187-219).

5 Decisión (PESC) 2015/778 del Consejo, de 18 de mayo de 2015, relativa a una operación militar de la Unión Europea en el Mediterráneo central meridional (EUNAVFOR MED), (DO L 122, de 19 de mayo de 2015, p. 31).

6 Decisión (PESC) 2015/1926 del Consejo, de 26 de octubre de 2015, por la que se modifica la Decisión (PESC) 2015/778 del Consejo relativa a una operación militar de la Unión Europea en el Mediterráneo central meridional (EUNAVFOR MED), (DO L 281, de 27 de octubre de 2015, p. 13).

7 Si en el 2011 —el momento más álgido en cuanto al número de ataques piratas constatados desde el inicio de la operación en 2008- hubo un total de 176 ataques, en el 2015 no se confirmó ninguno, y después se sigue aproximadamente la misma tónica. Véase a este respecto: EUNAVFOR Somalia, Facts and Figures. Disponible en: 
salvamiento y rescate que ya se desarrollaba con la operación Tritón de la Agencia Europea de la Guardia de Fronteras y Costas (Frontex) como para luchar contra el tráfico de personas en espacios internacionales o en el de terceros Estados, lo que necesariamente debía situarse en el marco de la PCSD con apoyo del Consejo de Seguridad de las Naciones Unidas (CSNU) ${ }^{8}$. Resulta obvia, no obstante, la estrecha ligazón de las actividades que debe realizar la operación Sophia con el control de las fronteras exteriores del Espacio de Libertad, Seguridad y Justicia (ELSJ), con lo que se subraya la necesidad creciente de coordinación entre PCSD y ELSJ.

Aunque en este trabajo nos centraremos en la operación Sophia, debemos poner de manifiesto que, también bajo el paraguas de la PCSD, la UE había puesto ya en marcha, el 22 de mayo de 2013, la Misión de la Unión Europea de Asistencia y Gestión Integrada de las Fronteras en Libia (EUBAM Libia) para cooperar con las autoridades de ese Estado a reforzar la seguridad de sus fronteras terrestres, marítimas y aéreas a corto plazo, y a largo plazo a desarrollar una estrategia amplia de gestión integral de las fronteras?. Hasta el 31 de diciembre de 2018, el mandato de EUBAM Libia se centraba en facilitar una reforma del sector de la seguridad en Libia y preparar el camino a una posible misión civil de la PCSD, colaborando estrechamente con la Misión de Apoyo de las Naciones Unidas en Libia (UNSMIL) ${ }^{10}$. Sin embargo, el 17 de

https://eunavfor.eu/key-facts-and-figures/. Esta referencia, como todas las demás, han sido recuperadas el 30 de mayo de 2019.

8 Sobre la inspiración de la operación Sophia en la operación Atalanta, véase también: Arteaga y González (2015: 4-5) y Faleg y Blockmans (2015: 2-4). Asimismo, acerca de la oportunidad y pertinencia de lanzar una operación militar para solventar el problema de la migración véase: Acosta Sánchez (2018: 34-41) o Himmrich (2019: 3).

9 Decisión 2013/233/PESC del Consejo, de 22 de mayo de 2013, sobre la Misión de la Unión Europea de asistencia y gestión integrada de las fronteras en Libia (EUBAM Libia) (DO L 138, de 24 de mayo de 2013, p. 15).

10 Como es lógico, la UE es bien consciente de que no puede resolver en solitario el problema de fondo de la migración proveniente de África, por lo que trata de actuar en cooperación con otros actores internacionales, como es el caso mencionado de la Misión UNSMIL, la Unión Africana o la Organización del Tratado del Atlántico Norte (OTAN), véase: Council of the European Union, Doc. 11471/18, EEAS, Strategic Review on EUNAVFOR MED Operation Sophia, EUBM Libya \& EU Liaison and Planning Cell, de 27.07.2018 [EEAS (2018) 835], p. 22. Por otro lado, EUBAM Libia y Sophia trabajan en coordinación con las misiones PCSD en el Sahel y con algunos Estados miembros de la UE, así como con otras acciones de la UE y de otras organizaciones internacionales europeas, como la Delegación de la UE en el Consejo de Europa (EUDEL), la Célula de Enlace y Planificación de la UE (EULPC), Europol, 
diciembre de 2018, el Consejo de la Unión Europea ha prolongado el mandato de EUBAM Libia hasta el 30 de junio de 2020 y ampliado sus competencias con objeto de ayudar a las autoridades libias a la desarticulación de las redes de delincuencia organizada dedicadas al tráfico ilícito de migrantes, a la trata de seres humanos y al terrorismo ${ }^{11}$.

Como ya hemos avanzado más arriba, el objetivo inicial de la operación Sophia era el de desarticular el modelo de negocio de las redes de tráfico ilícito y de trata de personas en el Mediterráneo central meridional, realizando esfuerzos sistemáticos para detectar, capturar y eliminar los buques y medios que utilizaran aquellos criminales, de conformidad con el derecho internacional aplicable, incluidos la Convención de Naciones Unidas sobre Derecho del Mar (CNUDM) y las resoluciones que al efecto emitiera el CSNU ${ }^{12}$.

Por otro lado, la operación se debía desarrollar en tres fases consecutivas. En la primera fase, Sophia debía apoyar la detección y el seguimiento de las redes de migración mediante recopilación de información y la realización de patrullas en alta mar, de conformidad con el derecho internacional. En la segunda fase, la operación naval debía, inicialmente, proceder a visitar, registrar, apresar y desviar en alta mar los buques sospechosos de ser utilizados para el tráfico ilícito o la trata de seres humanos, en las condiciones previstas en el derecho internacional aplicable, incluidos la CNUDM y el Protocolo contra el Tráfico Ilícito de Migrantes. Posteriormente, en un momento ulterior de la segunda fase, la operación, de conformidad con cualquier resolución aplicable del CSNU o el consentimiento del Estado ribereño en cuestión, debía proceder a visitar, registrar, apresar y desviar, en alta mar y en las aguas interiores de dicho Estado, los buques sospechosos de ser utilizados para el tráfico ilícito o la trata de seres humanos, en las condiciones establecidas en dicha resolución o por el consentimiento estatal esperado. Finalmente, en la tercera fase, de conformidad con las resoluciones oportunas del CSNU o el consentimiento del Estado ribereño en cuestión, la operación debía adoptar todas las medidas necesarias, incluso la eliminación

Eurojust, el Programa de Apoyo a la Gestión Integrada de Fronteras y Migración en Libia (EUTF), Frontex y el Proyecto Seahorse. Véase ibid., p. 49. Iremos abordando la labor de algunos de estos actores con más detenimiento más adelante.

11 Decisión (PESC) 2018/2009 del Consejo, de 17 de diciembre de 2018, por la que se modifica y prorroga la Decisión 2013/233/PESC sobre la Misión de la Unión Europea de asistencia y gestión integrada de las fronteras en Libia (EUBAM Libia), (DO L 322, de 18 de diciembre de 2018, p. 25).

12 Decisión (PESC) 2015/778 del Consejo, de 18 de mayo de 2015, relativa a una operación militar de la Unión Europea en el Mediterráneo central meridional (EUNAVFOR MED), (DO L 122, de 19 de mayo de 2015, p. 31). 
o inutilización, contra los buques y los medios relacionados que se sospeche que se utilizan para el tráfico ilícito o la trata de seres humanos en el territorio de dicho Estado, en las condiciones establecidas por dichas resoluciones del CSNU o por el Estado ribereño ${ }^{13}$.

Pocos meses más tarde, la Resolución del CSNU $2240(2015)^{14}$ proveyó la base legal necesaria para implementar alguna de las medidas previstas por el Consejo de la UE en su Decisión (PESC) 2015/778, dándole, además, un trascendental espaldarazo político ${ }^{15}$.

Subsiguientemente, el Consejo de la UE ha ido prorrogando la operación Sophia y añadiéndole nuevos objetivos, de acuerdo con las indicaciones del CSNU. Así, en junio de $2016^{16}$ se le sumaron dos nuevas tareas de apoyo: por un lado, la formación y capacitación de la Guardia Costera y la Armada libias para la realización de actividades de control marítimo, en especial para luchar contra el tráfico ilícito y la trata de personas; y por otro lado, la implementación del embargo de armas que el CSNU había impuesto en alta mar frente a las costas de Libia mediante su Resolución 2292 (2016) de 14 de junio de 2016.

Unos meses más tarde, en julio de 2017, se encargó a Sophia llevar a cabo actividades de vigilancia y recopilar información sobre el tráfico ilegal de petróleo crudo y de otros productos con el que se financian las mafias trafi-

13 Ibid., arts. 1 y art. 2 respectivamente. El 7 de octubre de 2015, se pasó a la segunda fase de la operación; véase: Decisión (PESC) 2015/1772 del Comité Político y de Seguridad, de 28 de septiembre de 2015, relativa a la transición de EUNAVFOR MED a la segunda fase de la operación, con arreglo al art. 2, apdo. 2, letra b), inciso i), de la Decisión (PESC) 2015/778 relativa a una operación militar de la Unión Europea en el Mediterráneo central meridional (EUNAVFOR MED) (EUNAVFOR MED/2/2015), (DO L 258, de 3 de octubre de 2015, p. 5). Sobre un análisis más profundo de las cuestiones relativas al derecho internacional del mar en lo atinente a las medidas previstas para las diversas fases de la operación Sophia, véase Butler y Ratcovich (2016: 245-251).

14 Consejo de Seguridad de las Naciones Unidas, Resolución 2240 (2015), de 9 de octubre de 2015, ONU Doc. S/RES/2240 (2015).

15 En este sentido véase: «Statement of the HR/VP Federica Mogherini on the vote of UN resolution 2240 on EU naval operation in the Mediterranean", 09/10/2015. Disponible en: https://bit.ly/31 KfqfC.

16 Decisión (PESC) 2016/993 del Consejo, de 20 de junio de 2016, por la que se modifica la Decisión (PESC) 2015/778 relativa a una operación militar de la Unión Europea en el Mediterráneo central meridional (operación EUNAVFOR MED SOPHIA), (DO L 162, de 21 de junio de 2016, p. 18). 
cantes de personas ${ }^{17}$ siguiendo el mandato del CSNU establecido mediante su Resolución 2146 (2014), de 19 de marzo de 2014.

No bastando con ello, en mayo de 2018, el Consejo decidió crear una Célula de Información sobre Delincuencia compuesta por personal de las autoridades policiales pertinentes de los Estados miembros y de los organismos de la Unión con el fin de facilitar el tratamiento y la transmisión de la información relativa a las competencias de la operación, sobre todo aquella que concierne a la trata y el tráfico de seres humanos o el embargo de armas a Libia ${ }^{18}$. No cabe duda de que, dado el número de actores implicados y de la complejidad de las actividades que deben realizar, a caballo entre la PCSD y el ELSJ, esta célula puede resultar un foro de comunicación de información y experiencias clave en el devenir de los esfuerzos de la lucha contra la inmigración ilegal en la zona.

Ya en los últimos meses, debido a la amenaza italiana de vetar la operación si no se llegaba a una decisión general sobre migraciones en la que se fijara una distribución de los migrantes entre los distintos Estados miembros tras su desembarque en los puertos italianos, el porvenir de Sophia quedó en entredicho. Así, como era previsible, el 21 de diciembre de 2018 el Consejo decidió prolongar la operación, pero esta vez solo por tres meses, hasta el 31 de marzo de $2019^{19}$, lo que motivó que Alemania, viendo el panorama, retirara el navío de su nacionalidad que participaba en esos momentos en las tareas de Sophia ${ }^{20}$.

Finalmente, el Consejo, tras muchas discusiones, el 29 de marzo de 2019 prorrogó la operación Sophia hasta el 30 de septiembre de $2019^{21}$, aunque

17 Decisión (PESC) 2017/1385 del Consejo, de 25 de julio de 2017, por la que se modifica la Decisión (PESC) 2015/778 relativa a una operación militar de la Unión Europea en el Mediterráneo central meridional (operación EUNAVFOR MED SOPHIA), (DO L 194, de 26 de julio de 2017, p. 61).

18 Decisión (PESC) 2018/717 del Consejo, de 14 de mayo de 2018, por la que se modifica la Decisión (PESC) 2015/778 relativa a una operación militar de la Unión Europea en el Mediterráneo central meridional (operación EUNAVFOR MED SOPHIA), (DO L 120, de 16 de mayo de 2018, p. 10). Sobre la Célula de Información y su labor, véase el documento Doc. 11471/18, EEAS, Strategic Review on EUNAVFOR MED Operation Sophia..., op. cit., p. 16.

19 Decisión (PESC) 2018/2055 del Consejo, de 21 de diciembre de 2018, por la que se modifica la Decisión (PESC) 2015/778 relativa a una operación militar de la Unión Europea en el Mediterráneo central meridional (operación EUNAVFOR MED SOPHIA), (DO L 327, de 21 de diciembre de 2018, p. 9).

20 Sobre este aspecto véase: «Germany pulls out of Mediterranean migrant mission Sophia». Disponible en: https://bit.ly/32NRE3E.

21 Decisión (PESC) 2019/535 del Consejo, de 29 de marzo de 2019, por la que se modifica la Decisión (PESC) 2015/778 relativa a una operación militar de la Unión 
ha decidido suspender temporalmente el despliegue de los medios navales durante esta prórroga, lo que le priva, en mi opinión, siendo una operación naval, de casi todo sentido. Se alega, no obstante, que durante estos meses la operación seguirá ocupándose de la vigilancia aérea así como de apoyar y formar a la Guardia Costera y a la Armada libias ${ }^{22}$.

En definitiva, a la luz de estos acontecimientos que hemos presentado asépticamente y poseyendo ya una buena perspectiva de su trayectoria, entendemos que nos encontramos en una coyuntura excelente para ir analizando los elementos que han llevado a que Sophia se encuentre en la situación actual y a hacer balance de los resultados, determinando si ha sido un éxito o un fracaso a contabilizar en el debe o en el haber de la PCSD de la UE. A este objetivo dedicamos este trabajo.

Con este fin, en una primera instancia llevaremos a cabo una exposición de los logros - tanto positivos como negativos - atribuibles en estos años a los barcos y hombres de Sophia y, en una segunda instancia, realizaremos, por el contrario, una reflexión acerca de los elementos externos o coyunturales que han motivado que la operación se haya ido desdibujando con el tiempo - ya que ha ido descargando poco a poco sus competencias iniciales en los buques y fuerzas de seguridad de Libia- y se encuentre en la actualidad en una situación muy delicada, toda vez que sus buques han tenido que retornar a puerto.

Más concretamente, nuestro artículo se estructurará de la siguiente manera: en la segunda sección analizaremos las consecuciones de la operación: ¿qué resultados, tanto positivos como negativos, ha alcanzado tras casi cuatro años en el mar? En la tercera sección reflexionaremos sobre el papel que ha jugado el CSNU para que la operación Sophia se encuentre en este impasse temporal, pero que puede que acabe en un verdadero encallamiento. En la cuarta sección estudiaremos la influencia de la actitud de Italia en la evolución de la operación y en particular en su situación presente. En la quinta sección abordaremos los efectos que ha tenido en la situación actual el hecho de la colaboración de los efectivos de la Marina de Libia. Finalmente, presentaremos nuestras conclusiones.

Europea en el Mediterráneo central meridional (operación EUNAVFOR MED SOPHIA), (DO L 92, de 1 de abril de 2019, p. 1).

22 Véase Consejo de la UE, Comunicado de prensa, 29 de marzo de 2019, «Operación EUNAVFOR MED SOPHIA: se prorroga el mandato hasta el 30 de septiembre de 2019». Disponible en: https://bit.ly/2JnvBJD. 


\section{LOS RESULTADOS DE LA OPERACIÓN SOPHIA HASTA EL MOMENTO}

Antes de poner el foco en los resultados específicos de la operación Sophia, conviene resaltar que el conjunto de las medidas que ha adoptado la UE desde 2015 para asegurar el control efectivo de las fronteras exteriores de la UE ha dado, en general, buenos resultados ${ }^{23}$, de manera que el número de cruces ilegales de fronteras detectados hacia la UE se ha reducido en un $95 \%$ en comparación con las cifras que se alcanzaron en octubre de 2015 cuando la crisis migratoria explotó alcanzando cifras máximas, si bien recientemente ha habido un repunte de los flujos en las rutas del Mediterráneo oriental y occidental ${ }^{24}$.

En cuanto al número de migrantes irregulares que intentaron alcanzar Europa por la ruta del Mediterráneo central, según datos suministrados por Frontex, en el 2014 se contabilizó un total de 170664 personas, mientras que en el año del inicio de la operación Sophia, 2015, se pasó a 153946 personas. El máximo se alcanzó en 2016, cuando intentaron cruzar el Mediterráneo irregularmente por esta vía 181376 personas. En 2017 se constataron un total de 118962 personas. Por su parte, en 2018 hubo un gran descenso en el número de intentos de alcanzar las costas italianas, pues se contaron 23485 personas, lo que, en comparación con las cifras alcanzadas otros años, es significativamente inferior ${ }^{25}$.

Al mismo tiempo, el número de personas que intentaron cruzar el Mare Nostrum por la ruta occidental creció en una importante proporción. Así, en 2017 se alcanzó la cifra de 23063 de personas que trataron de llegar a España ${ }^{26}$, mientras que en 2018 se llegó al récord de 57034 personas $^{27}$, el mayor número desde $2009^{28}$. No obstante, de acuerdo con Frontex, la presión sobre

23 Si de buenos resultados se puede hablar cuando se trata de frenar la migración de personas en extrema necesidad. En este sentido, véase también Steinhilper y Gruijters (2018: 529-530) y Vacas Fernández (2016: 115-117).

24 Consejo Europeo, Conclusiones de la Reunión del Consejo Europeo, de 28 de junio de 2018, Migración, punto 1.

25 Todas las cifras señaladas provienen de: Frontex, «Illegal border crossings on the Central Mediterranean route (including Apulia and Calabria) in numbers». Disponible en: https://bit.ly/32O1bYu.

26 Frontex, «Illegal border crossings on the Western Mediterranean route (sea and land) in numbers». Disponible en: https://bit.ly/2oi1P1z.

27 Ibid.

28 Frontex, «Focus on Western Mediterreanean route: Frontex in Spain». Disponible en: https://bit.ly/363ku24. 
las mafias migratorias que haya podido ejercer la operación Sophia en la vía del Mediterráneo central no se encuentra entre las causas del repunte del tránsito por la vía occidental ${ }^{29}$.

Más importante, y por supuesto dramática, es la cifra de las personas que perdieron su vida intentando cruzar a Europa desde África por la ruta del Mediterráneo central, que es considerada la ruta de migración más mortífera del mundo por la Organización Mundial de las Migraciones (IOM por sus siglas en inglés) ${ }^{30}$. Más concretamente, en 2014 fallecieron 3165 personas; en 2015, 3149; en 2016, 4581; en 2017, 2853; y en 2018 la cifra bajó a la mitad aproximadamente, toda vez que perecieron 1314 personas y, en 2019, hasta el final de mayo, $321^{31}$.

Para la IOM, en 2017 hubo un fuerte descenso en el número de naufragios a gran escala, que traen consigo cientos de muertes, lo que puede indicar que los esfuerzos de rescate y salvamento en el Mediterráneo central son cada vez más efectivos ${ }^{32}$, y ello, en buena medida, creemos, que se debe a las diversas acciones que configuran la operación Sophia, aunque no exclusivamente, pues habría que tener en cuenta las acciones realizadas por los otros actores implicados en las mismas tareas. En cualquier caso, de acuerdo con fuentes oficiales de la UE, desde su inicio la operación Sophia ha ayudado a salvar más de 45000 vidas $^{33}$.

A la luz de estos datos, sería injusto no reconocer que, al menos en materia de salvamento y rescate, la operación Sophia no ha hecho un mal trabajo ${ }^{34}$. Habría que determinar, no obstante, si para ese viaje se necesitaban alforjas, o lo que es lo mismo, si era conveniente utilizar buques de guerra, de naturaleza

29 Ibid.

30 En este sentido véase: IOM's Global Migration, Data Analysis Centre, GMDAC, «The Central Mediterranean route: Migrant Fatalities, January 2014-July 2017». Disponible en: https://bit.ly/2NhtuYK.

31 Todas las cifras señaladas provienen de: International Organization for Migration, Missing Migrants. Tracking Deaths Along Migratory Routes, Central Mediterranean. Disponible en: https://bit.ly/2omYcYg.

32 Ibid.

33 A este respecto, véase: Doc. 11471/18, EEAS, Strategic Review on EUNAVFOR MED Operation Sophia..., op. cit., p. 25.

34 Así lo piensa también la alta representante de la Unión para Asuntos Exteriores y Política de Seguridad, como lo señaló en una carta de 26 de julio de 2017, en la que se mostró en desacuerdo con las apreciaciones de la House of Lords según las cuales la operación es un fracaso. Disponible en: https://bit.ly/2MKh5xC. En este sentido, véase asimismo Poncela Sancho (2019: 11). 
esencialmente disuasoria, para tareas que otro tipo de embarcaciones y de personal pueden desarrollar quizá de forma globalmente más apropiada.

Otra cuestión es la eficacia de la labor de la operación Sophia en la lucha contra las mafias dedicadas a la trata y el tráfico de personas; aunque hay que reconocer que las circunstancias son complejas y, en buena medida, escapan al control de la UE, ya que la gran parte de los mafiosos no están radicados en Europa y los que a la postre son apresados en las embarcaciones que cruzan el Mediterráneo no son sino el último eslabón de la cadena criminal ${ }^{35}$. Sobre estos aspectos parece que la UE va siendo cada vez más reacia a publicar las verdaderas cifras en el sitio web de la operación ${ }^{36}$, aunque por otras fuentes se podía constatar, hace unos meses, cómo se habían aprehendido unos 148 sospechosos de incurrir en el tráfico de personas y se habían inutilizado unos 550 bienes de los mafiosos ${ }^{37}$.

Posiblemente, estas cifras no sean espectaculares. Desde luego, han sido criticadas duramente por algunos observadores, entre otros por los autores del informe elaborado al efecto por la House of Lords del Reino Unido, para quien la operación naval de la UE no había conseguido desactivar el modelo de negocio de los traficantes y contrabandistas de personas, sino que incluso había tenido como efecto perverso que se emplearan, en sus actividades criminales, embarcaciones de menor calidad que antes de que los buques de la UE surcaran el Mediterráneo, con lo que el porcentaje de muertes se había incrementado ${ }^{38}$.

Sin embargo, desde nuestro punto de vista, esas críticas resultarían exageradas, pues, como ha puesto de manifiesto la UE, con la presencia de los buques de Sophia en alta mar, la actividad de los traficantes se ha reducido mucho en esa zona, limitándose a operar, en consecuencia, en las aguas terri-

35 En este sentido véase Comisión Europea, «Una agenda europea de migración», Comunicación de la Comisión al Parlamento Europeo, al Consejo, al Comité Económico y Social Europeo y al Comité de las Regiones, COM(2015) 240 final, de 13 de mayo de 2015, p. 10.

36 Véase, por ejemplo, Press Release, «EUNAVFORMED operation SOPHIA seizes weapons on board a vessel in International waters», https://bit.ly/2Pj9BTT.

37 A este respecto, véase Doc. 11471/18, EEAS, Strategic Review on EUNAVFOR MED Operation Sophia..., op. cit., p. 25. En relación con el modo de llevar a cabo las tareas de identificación de sospechosos para su posterior detención y enjuiciamiento, véase Poncela Sancho (2019: 9-11).

House of Lords, European Union Committee, 2nd Report of Session 2017-19, Operation Sophia: a failed mission, p. 14, párr. 45. Por el contrario, Federica Mogherini, la alta representante de la Unión para Asuntos Exteriores y Política de Seguridad, en su carta de 26 de julio de 2017 antes citada, se mostró en desacuerdo en las apreciaciones de la House of Lords. 
toriales libias, con lo que su modelo de negocio se habría visto severamente afectado $^{39}$. Por otro lado, la actuación de Sophia en alta mar ha tenido un impacto favorable sobre la actividad de los buques comerciales en la zona al liberarlos en parte de la tarea de realizar labores de salvamento y rescate, con lo que se evita, además, la interrupción de la ruta ${ }^{40}$.

Finalmente, en lo tocante a los otros objetivos que se han ido añadiendo a lo largo del tiempo al mandato de Sophia, podemos constatar cómo, según fuentes oficiales de la operación, se ha entrenado a unos 355 miembros de la Guardia Costera y de la Armada de Libia ${ }^{41}$, lo que en el futuro podría permitir a los cuerpos y fuerzas de seguridad de este Estado ocuparse de mantener el orden en los espacios sometidos a su jurisdicción cuando la situación política se normalice en ese país, lo que evitaría que la UE deba actuar como una especie de gendarme mundial y proyectar sombras sobre el principio de no intervención en los asuntos internos de otros Estados. Junto a ello, de acuerdo con las estimaciones del secretario general de las Naciones Unidas en mayo de 2018, desde junio de 2016 hasta junio de 2017 se habían interceptado más de 1200 buques, se habían realizado más de 70 acercamientos amistosos, y se habían inspeccionado tres buques, lo que culminó en dos decomisos de artículos prohibidos. Por otro lado, desde junio de 2017 hasta mayo de 2018 la operación militar no había detectado actividades de contrabando de armas en aguas internacionales ${ }^{42}$.

\section{EL PAPEL DEL CONSEJO DE SEGURIDAD DE LAS NACIONES UNIDAS EN EL ENCALLAMIENTO ACTUAL DE LA OPERACIÓN SOPHIA}

Ya se ha mencionado que la Resolución del CSNU 2240 (2015) proveyó la base legal necesaria para implementar alguna de las medidas previstas por el Consejo de la UE en su Decisión (PESC) 2015/778 que lanzó los buques europeos al Mediterráneo y, por supuesto, le dio un trascendental espaldarazo político.

39 Doc. 11471/18, EEAS, Strategic Review on EUNAVFOR MED Operation Sophia..., op. cit., p. 26.

40 Ibid., pp. 5-6.

41 Véase al respecto EUNAVFOR MED, Operation Sophia, «Mission at a glance». Disponible en: https://bit.ly/2JISKfr.

42 Consejo de Seguridad, Aplicación de la resolución 2357 (2017), Informe del Secretario General, de 11 de mayo de 2018, ONU Doc. S/2018/451, punto 7. 
Conviene hacer notar que el CSNU adoptó su Resolución 2240 (2015), y con ella una serie de medidas extraordinarias en el ámbito del derecho internacional del mar, sobre la base jurídica del capítulo VII de la Carta de las Naciones Unidas. El CSNU se justificó explícitamente en que la Carta de las Naciones Unidas le confiere la responsabilidad primordial de mantener la paz y la seguridad internacionales y en atención a la consideración implícita de que el tráfico de migrantes supone un peligro muy serio a la paz y seguridad internacionales ${ }^{43}$.

Sin embargo, aquella resolución del CSNU no autorizó las extraordinarias medidas contra el tráfico de migrantes y la trata de personas establecidas por el Consejo de la UE en el nacimiento de la operación Sophia en relación con las aguas y el territorio terrestre de Libia. De hecho, durante las deliberaciones para adoptar la que luego devendría la Resolución del CSNU 2240 (2015), varios miembros del CSNU opusieron resistencia a alguno de los elementos esenciales de la misma: por un lado, a una excesivamente amplia autorización de uso de la fuerza por parte de los buques y el personal de las fuerzas internacionales, y por otro lado, a las limitaciones a la jurisdicción en alta mar del Estado del pabellón que la resolución suponía ${ }^{44}$. De esta forma, podemos lícitamente pensar que si ya suscitó problemas el ejercicio del uso de la fuerza en alta mar por parte de la operación Sophia, mucho más suscitaría el uso de la fuerza en las aguas territoriales y en el territorio terrestre de Libia en el futuro.

Como era de suponer, tampoco han autorizado a operar en las aguas o el espacio terrestre de Libia las resoluciones del CSNU que han ido confirmando y prorrogando posteriormente, de doce en doce meses, las medidas adoptadas en virtud de su Resolución 2240 (2015), a saber las resoluciones 2312 (2016), de 6 de octubre de $2016^{45}, 2380$ (2017), de 5 de octubre de $2017^{46}$ y 2437 (2018), de 3 de octubre de $2018^{47}$.

43 Sobre la tendencia del CSNU a ligar la seguridad con la protección internacional de refugiados y migrantes, véase Gowlland-Debbas (2007: 290-292).

44 En este sentido véase Security Council Report, What's in blue. Insights of the work of the UN Security Council, "Vote on a Resolution on Human Trafficking and Migrant Smuggling in the Mediterranean, 8 October 2015». Disponible en: https://bit. ly/2on11IQ.

45 Consejo de Seguridad, Resolución 2312 (2016), de 6 de octubre de 2016, ONU Doc. S/RES/2312 (2016).

46 Consejo de Seguridad, Resolución 2380 (2017), de 5 de octubre de 2017, ONU Doc. S/RES/2380(2017).

47 Consejo de Seguridad, Resolución 2437 (2018), de 3 de octubre de 2018, ONU Doc. S/RES/2437(2018). 
Junto a esta línea de actuación de lucha contra el tráfico de personas en el Mediterráneo, en el contexto de la situación de Libia el CSNU ha seguido otras vías de lucha contra otras actividades delictivas, como el tráfico de armas o la exportación ilícita de petróleo, autorizando a buques de terceros Estados a inspeccionar en alta mar los buques sospechosos de dedicarse a esas actividades. Estas autorizaciones, como es lógico, están muy relacionadas con las que se han ido concediendo en la lucha contra el tráfico de personas, por lo que, poco a poco, como vimos más arriba, la UE fue encargando a los buques de la operación Sophia que se ocuparan también de luchar contra el tráfico de armas y la exportación ilícita de petróleo.

En relación con el tráfico de armas, el 14 de junio de 2016, el CSNU adoptó su Resolución 2292 (2016) sobre el embargo de armas a Libia, mediante la cual, para evitar que los grupos terroristas en Libia declarasen su lealtad a Dáesh o a Al-Qaeda y que la situación en Libia se viera exacerbada por el contrabando de armas ilícitas y de material conexo, el CSNU endureció y extendió las condiciones del embargo de armas que había ido imponiendo en los últimos años a partir de su Resolución 1970 (2011) ${ }^{48}$. La Resolución del CSNU 2292 (2016) autorizó, en particular, a los Estados miembros a que, actuando a título nacional o por conducto de organizaciones regionales, inspeccionasen, en alta mar frente a las costas de Libia, los buques que tuvieran su origen o su destino en Libia y sobre los que existiesen motivos razonables para creer que transportasen armas o material conexo a Libia o desde su territorio, directa o indirectamente, en contravención de sus resoluciones anteriores sobre el embargo ${ }^{49}$. Posteriormente, estas autorizaciones han sido renovadas y prorrogadas en el tiempo sucesivamente por las resoluciones 2357 (2017), de 12 de junio de $2017^{50}$ y 2420 (2018), de 11 de junio de $2018^{51}$.

Acerca de la exportación ilícita de petróleo de Libia, que conlleva una pérdida de renta para el país y alimenta aún más las redes criminales en la zona $^{52}$, el CSNU autorizó a los buques de terceros Estados, mediante su Reso-

48 Consejo de Seguridad, Resolución 1970 (2011), de 26 de febrero de 2011, ONU Doc. S/RES/1970 (2011).

49 Consejo de Seguridad, Resolución 2292 (2016), de 14 de junio de 2016, ONU Doc. S/RES/2292 (2016).

50 Consejo de Seguridad, Resolución 2357 (2017), de 12 de junio de 2017, ONU Doc. S/RES/2357(2017).

51 Consejo de Seguridad, Resolución 2420 (2018), de 11 de junio de 2018, ONU Doc. S/RES/2420(2018).

52 Council of the European Union, Doc. 11471/18, EEAS, Strategic Review on EUNAVFOR MED Operation Sophia, EUBM Libya \& EU Liaison and Planning Cell, de 27.07.2018 (EEAS (2018) 835), p. 4. 
lución 2146 (2014), de 19 de marzo de 2014, a que inspeccionen en alta mar los buques sospechosos de estar involucrados en ese tráfico ilícito ${ }^{53}$. En virtud de su Resolución 2441 (2018), de 5 de noviembre de 2018 $8^{54}$, ha decidido prorrogar hasta el 15 de febrero de 2020 las autorizaciones conferidas y las medidas impuestas por la Resolución 2146 (2014).

Como hemos podido apreciar, en ninguna de las resoluciones que ha dictado el CSNU hasta la fecha para luchar contra el tráfico de personas en el Mediterráneo, o contra el tráfico de armas y la exportación ilícita de petróleo desde Libia, se ha concedido la autorización a los Estados miembros de la ONU, individualmente o a través de las organizaciones internacionales regionales, a actuar en el mar territorial o en el territorio terrestre de Libia. Esta circunstancia convierte en imposible, por tanto, el paso a las fases más avanzadas de la operación Sophia, salvo que se cuente con el consentimiento del Estado costero. Pero la situación en Libia, como veremos más adelante, lo ha imposibilitado por el momento.

Finalmente, debemos reseñar una contribución del CSNU distinta a las que venimos considerando hasta el momento, pero estrechamente ligada a ellas, toda vez que se basa en sanciones individuales a personas sospechosas de haber llevado a cabo las conductas previstas en la Resolución 1970 (2011) relativa a Libia consistentes en graves violaciones de los derechos humanos. Como es sabido, la citada resolución del CSNU estableció un Comité de Sanciones que elaboraría una lista de personas presuntamente culpables de esas conductas y sometidas a sanciones nada desdeñables, como la imposibilidad de viajar o la congelación de bienes. Pues bien, en relación con la actividad del Comité de Sanciones en cuestión, cabe destacar que, el 7 de junio de 2017, se incluyó en la lista de personas sujetas a las sanciones previstas, por primera vez, a seis personas supuestamente involucradas en el tráfico de migrantes y la trata de personas ${ }^{55}$. Entre las nuevas personas incluidas en la lista se encontraban el jefe regional de la Guardia Costera de Zawiya y dos comandantes de milicias libias ${ }^{56}$.

53 Consejo de Seguridad, Resolución 2146 (2014), de 19 de marzo de 2014, ONU Doc. S/RES/2146 (2014).

54 Consejo de Seguridad, Resolución 2441 (2018), de 5 de noviembre de 2018, ONU Doc. S/RES/2441(2018).

55 Véase en este sentido Consejo de Seguridad, Aplicación de la resolución 2380 (2017), Informe del Secretario General, de 31 de agosto de 2018, ONU Doc. S/2018/807, párr. 31.

56 Sobre este aspecto véase Security Council Report. What's in blue. Insights of the work of the UN Security Council, «Libya: Reauthorisation of Maritime Interdiction 


\section{EL PAPEL DE ITALIA EN LA DERIVA Y EN LA PARÁLISIS PRESENTE DE LA OPERACIÓN}

Desde el año 2004 Italia venía ocupándose de controlar los flujos migratorios en el Mediterráneo central desplegando permanentemente un buque en el estrecho de Sicilia junto con aviones de vigilancia marítima. Sin embargo, debido a la elevación a niveles dramáticos de esos flujos en el 2013, se decidió por lanzar la operación militar/humanitaria Mare Nostrum el 18 de octubre de 2013, con el doble objetivo de proteger la vida humana en el mar y de tratar de llevar ante la justicia a los tratantes de personas y los traficantes de migrantes ${ }^{57}$.

En este contexto, cabe recordar que la obligación de prestar auxilio a las personas que se encuentren en peligro de desaparecer en el mar es un principio básico del derecho internacional del mar, presente en los más importantes instrumentos convencionales en la materia ${ }^{58}$, y con un origen claro en el derecho consuetudinario, tal como reconoció la Comisión de Derecho Internacional (CDI) en 195659. Recogida en el art. 98 de la CNUDM, la obligación de auxilio pone sobre los hombros del Estado del pabellón la carga de exigir a los capitanes de los buques que lo enarbolan que rescaten a las personas en riesgo de perderse en el mar; exigencia que se aplica a todo tipo de buque y en todos los espacios marítimos ${ }^{60}$. Pero, al mismo tiempo, las disposiciones del art. 98 CNUDM recuerdan el deber de los Estados ribereños de establecer y mantener servicios de búsqueda y rescate, aunque el alcance de esta exigencia, que está en el centro de toda la polémica que estamos viviendo en los últimos años en el Mediterráneo, no es evidente ${ }^{61}$. Recordemos que, entre otras cosas,

and Addition of Names to Sanctions List. 8 June 2018». Disponible en: https://bit. ly/367KcCq.

57 En este sentido véase Ministero della Difesa, Marina Militare, «Mare Nostrum Operation». Disponible en: https://bit.ly/2qIfbVz.

58 Art. 98 CNUDM, de 10 de diciembre de 1982, U.N.T.S. Vol. 1834, 1-31363, p. 371; la regla 33 del capítulo V del Convenio Internacional para la Seguridad de la Vida Humana en el Mar (SOLAS), de 1 de noviembre de 1974, 1184 UNTS 278. SOLAS; el art. 2.1.10 del Convenio Internacional sobre Búsqueda y Salvamento Marítimos (SAR), de 27 de abril de 1979, U.N.T.S., Vol. 1405, 1-23489, p. 118; el art. 10 del Convenio Internacional sobre Salvamento Marítimo, de 28 de abril de 1989, U.N.T.S. Vol. 1953. 1-33479, p. 165.

59 Comisión de Derecho Internacional, Anuario de la Comisión de Derecho Internacional, Vol. 2, 1956, A/CN.4/SER.A/1956/Add.1, p. 278.

60 A este respecto, véase Papanicolopulu (2016: 495-498).

61 Ibid., p. 498. 
para concretar y desarrollar esta última exigencia se adoptó en 1979 el Convenio SAR, que tiene por objeto la elaboración de un plan internacional de búsqueda y salvamento, que con el paso del tiempo ha servido para atribuir a las partes en el mismo una zona de búsqueda y salvamento delimitada —zonas SAR - de la cual son responsables. Por otro lado, una vez salvadas las personas en peligro, el capitán del barco que ha procedido al rescate asume dos nuevas obligaciones: en primer lugar, tratar a esas personas con humanidad, de conformidad con las obligaciones derivadas de los tratados de derechos humanos ${ }^{62}$, y en segundo lugar, llevar a aquellas personas a un lugar seguro ${ }^{63}$, lo que está ligado al problema del desembarco.

El desembarco está sometido a dos principios jurídicos. El primero, que se deriva de la soberanía ejercida por los Estados sobre su territorio, establece que no existe derecho de entrada en los puertos de un Estado, por lo que el buque que quiera desembarcar a las personas rescatadas en el mar en los puertos de un Estado debe obtener el consentimiento de ese Estado. El segundo principio es el de no devolución —non-refoulement-, que prohíbe que las personas rescatadas sean devueltas a las fronteras de los Estados en los que su vida o su libertad pueda ser amenazada, o donde puedan ser sometidos a torturas $u$ otros tratos o penas inhumanos o degradantes ${ }^{64}$. No obstante, no hay consenso para adoptar una regla general que predetermine el puerto de desembarque específico para cada incidente, es decir, el lugar seguro en el que deben dejarse las personas rescatadas. Tras la revisión de 2004, el art. 3.1.9. del Convenio SAR establece simplemente al respecto que el Estado en cuya zona SAR se lleva a cabo una operación de rescate debe tomar la iniciativa para encontrar un Estado dispuesto a aceptar el desembarco.

Volviendo a la operación italiana Mare Nostrum, debemos hacer notar que la misma se mantuvo activa hasta octubre de 2014, llegando a salvar a unas 150000 personas en aguas territoriales libias e internacionales ${ }^{65}$. De-

62 Resolución 167 (78), Directrices respecto de la actuación con las personas rescatadas en el mar, MSC 78/26/Add.2 ANEXO 34, 5.1.2.

63 Convenio SAR, Enmiendas de 1998, aprobadas por Resolución MSC.70(69), capítulo 1.3.2. Véase también sobre este particular: Resolución 167 (78), Directrices respecto de la actuación con las personas rescatadas en el mar, MSC 78/26/Add.2 ANEXO 34, 6.12-6. 18.

64 En este sentido véase Tribunal Europeo de Derechos Humanos, Chahal contra Reino Unido [GS], n.o 22414/93, 15 de noviembre de 1996, parr. 74. Véase, además, Papanicolopulu (2016: 500).

65 IOM, «Life Saving Mare Nostrum Operation Not a Migrant Pull Factor», Press Release, 31 October 2014. Disponible en: https://www.iom.int/news/iom-applaudsitalys-life-saving-mare-nostrum-operation-not-migrant-pull-factor. 
bido a las dimensiones del problema, Italia consideró que no podía soportar sola toda la carga y pidió a la Unión que adoptara un protagonismo mayor, si bien en una primera instancia sus gestiones no dieron el fruto esperado ${ }^{66}$. Sin embargo, poco a poco, la UE comenzó a decidirse a tomar cartas en el asunto, en primer lugar, a través de Frontex, que lanzó la operación Tritón en noviembre de $2014^{67}$, siendo ulteriormente sustituida por la operación Themis y, en segundo lugar, como sabemos, con el establecimiento de la operación Sophia cuando la catástrofe humanitaria en el Mediterráneo estalló en abril de $2015^{68}$.

De este modo, y como es lógico por la proximidad física de las costas italianas a las libias, Sophia ha tenido siempre un marcado color italiano. En efecto, además del impulso transalpino en el origen, el cuartel general de la

66 En este sentido, véase Nováky (2018: 200).

67 Si bien Tritón ya no era una operación de búsqueda y rescate sino una operación de vigilancia de las fronteras exteriores y de control de la criminalidad, con un presupuesto y una zona de operaciones sustancialmente menor que la de Mare Nostrum, lo que fue duramente criticado en marzo de 2015 por el Alto Comisionado de las Naciones Unidas para los Refugiados (ACNUR), véase: «Central Mediterranean Sea Initiative, Action Plan", https://www.unhcr.org/531990199.html. Véase también Esteve (2015: 167). En el 2014 se adoptó un reglamento para regular las actividades de las operaciones marítimas llevadas a cabo por Frontex, al que debía ajustarse Tritón y luego Themis, y que puede servir, mutatis mutandi, de guía interpretativa para las operaciones marítimas de la UE en el marco de la PCSD, véase Reglamento (UE) n. ${ }^{\circ}$ 656/2014 del Parlamento Europeo y del Consejo, de 15 de mayo de 2014, por el que se establecen normas para la vigilancia de las fronteras marítimas exteriores en el marco de la cooperación operativa coordinada por la Agencia Europea para la Gestión de la Cooperación Operativa en las Fronteras Exteriores de los Estados miembros de la Unión Europea, (DO 189, de 7 de junio de 2014, p. 93); véase asimismo Esteve (2015: 170).

68 Asimismo, en el marco de Frontex se puso en marcha en 2013 el Sistema Europeo de Vigilancia de Fronteras (EUROSUR), con objeto de fomentar la cooperación entre los Estados miembros para prevenir la delincuencia grave como el tráfico de drogas y la trata de seres humanos, para, entre otras cosas, reducir las muertes de inmigrantes en el mar —véase Reglamento (UE) n. ${ }^{\circ}$ 1052/2013 del Parlamento Europeo y del Consejo, de 22 de octubre de 2013, por el que se crea un Sistema Europeo de Vigilancia de Fronteras (Eurosur), DO L 295, de 6 de noviembre de 2013, p. 11-. Eurosur ha ideado el Programa Sea Horse para poner en pie una red de comunicaciones seguras en el Mediterráneo para intercambiar información sobre migración irregular por mar y para formar y entrenar a los oficiales de fronteras y migración de los países de África del Norte. Sobre el proyecto véase el documento: Doc. 11471/18, EEAS, Strategic Review on EUNAVFOR MED Operation Sophia..., op. cit., p. 78. 
operación ha estado de forma constante en Italia, el comandante al mando de la operación ha sido desde el principio el vicealmirante Enrico Credendino, de nacionalidad italiana, e Italia ha sido uno de los Estados que más medios militares y humanos ha puesto a disposición de Sophia ${ }^{69}$.

Por otro lado, la Operación de la UE ha funcionado desde el principio sobre la base de que toda persona salvada en el mar era desembarcada en puertos italianos ${ }^{70}$, lo que ha constituido, precisamente, uno de los elementos que más gravosa la ha hecho a ese Estado ${ }^{71}$. Así, Italia comenzó a poner seriamente en cuestión la política migratoria en general de la UE y en particular la operación Sophia, procurando que se revisara aquella base de la operación, de tal manera que las personas salvadas en el mar desembarcaran en otros puertos y después se distribuyeran por el resto de Estados miembros ${ }^{72}$. En este sentido, en la reunión del Consejo Europeo de 28 de junio de 2018, en las conclusiones sobre migración, se afirmaba que era necesaria una flexibilización de las reglas de desembarco de la operación Sophia, y se avanzaba la posibilidad de crear plataformas regionales de desembarque en terceros Estados - en estrecha colaboración con ellos, ACNUR y la IOM-, donde se llevaría a cabo una especie de clasificación entre personas con derecho a recibir asilo y personas sin ese derecho ${ }^{73}$. A los pocos días, el ministro italiano de Asuntos Exteriores pidió por carta a la alta representante de la Unión para Asuntos Exteriores y Política de Seguridad que se revisara el plan operativo de la operación Sophia, de forma coherente con las conclusiones del Consejo Europeo del $28 \mathrm{de} \mathrm{junio}^{74}$. Sin embargo, ningún acuerdo se sustanció al respecto en los meses siguientes.

Poco a poco, debido a la negativa del resto de Estados miembros a aceptar las posiciones italianas en cuanto al cambio de las reglas de desembarco de la operación Sophia para que los migrantes fueran desembarcados en puertos

69 Véase, por ejemplo, el sitio internet de la operación Sophia: https://www.operationsophia.eu/.

70 Véase al respecto Doc. 11471/18, EEAS, Strategic Review on EUNAVFOR MED Operation Sophia..., op. cit., p. 29.

71 Véase, por ejemplo, Frontex, Press Release, «EU Member States and Frontex show support for Italy at meeting to discuss Operation Triton», de 20 de julio de 2017: Disponible en: https://bit.ly/2MNmcx5.

72 Véase, en este sentido, por ejemplo Le comunicazioni del Presidente del Consiglio Giuseppe Conte al Parlamento in vista del Consiglio europeo del 13 e 14 dicembre. Disponible en: https://bit.ly/2NbGVtt.

73 Consejo Europeo, Conclusiones de la Reunión del Consejo Europeo, de 28 de junio de 2018, Migración, punto 5.

74 Véase, en este sentido, Doc. 11471/18, EEAS, Strategic Review on EUNAVFOR MED Operation Sophia..., op. cit., pp. 12-13. 
distintos a los italianos, Italia radicalizó su postura y amenazó con vetar la operación y darla por terminada ${ }^{75}$.

A nadie se le escapa que la posición italiana constituye una circunstancia clave y central para el devenir de la operación, ya que, como se ha puesto de manifiesto, Italia es el Estado que siempre asumió el liderazgo, tanto en su gestación como en su desarrollo. Ello explica que, en ausencia de un acuerdo entre los Estados en el seno del Consejo, en diciembre de 2018 la operación se extendiera por solo tres meses, y en marzo de 2019, como se vio más arriba, se prorrogara hasta septiembre de 2019 , aunque privada de su dimensión marítima.

Paralelamente, Italia, que durante los momentos álgidos de la crisis migratoria y ante su propia incapacidad para gestionarla en solitario llegó a ver con buenos ojos la ayuda prestada por las organizaciones internacionales no gubernamentales (ONG) dedicadas al salvamento marítimo, varió su política hacia ellas y comenzó a acosarlas ${ }^{76}$, en particular a partir de la aparición de una serie de artículos en la prensa internacional a finales de $2016^{77}$, o de un informe de Frontex, publicado en febrero de 2017, que criticaba la acción de salvamento de las ONG por considerar que fomentaban el denominado «efecto llamada ${ }^{78}$. Por ejemplo, en marzo de 2017, el fiscal de Catania, Carmelo Zuccaro, anunció que su oficina había incoado una investigación exploratoria para examinar las operaciones de las ONG de salvamento en el Mediterráneo $^{79} \mathrm{y}$ varias comisiones parlamentarias fueron establecidas en Italia en

75 A este respecto, véase ANSA, «Italy says may leave Sophia if no EU deal», disponible en: https://bit.ly/2JojNqi. Véase también Rasche (2018: 4-5) o «Italy extends Operation Sophia for three months», Infomigrants, 11 December 2018, disponible en: https://bit.ly/346rFEL.

76 En este sentido véase Cusumano (2019: 107-108).

77 Véase, por ejemplo, el artículo de Duncan Robinson aparecido en Financial Times en diciembre de 2016, «EU border force flags concerns over charities' interaction with migrant smugglers», que se hace eco de supuestas filtraciones provenientes de Frontex acusando a las ONG de fomentar el efecto llamada o, incluso, alegando la perpetración de actividades de tráfico de personas en algún buque de estas organizaciones. El artículo está disponible en: https://on.ft.com/2JnbLhp.

78 Frontex, Risk Analysis for 2017, pp .32-33. Disponible en: https://bit.ly/32OiFE2.

79 Comitato parlamentare di controllo sull'attuazione dell'Accordo di Schengen, di vigilanza sull'attività di Europol, di controllo e vigilanza in materia di immigrazione. Resoconto stenografico. Seduta n. 41 di Mercoledì 22 marzo 2017. Indagine conoscitiva sulla gestione del fenomeno migratorio nell'area Schengen, con particolare riferimento alle politiche dei paesi aderenti relative al controllo delle frontiere esterne e dei confini interni. Disponible en: https://bit.ly/2MJgY5g. 
los meses siguientes. No obstante, en ninguna de esas ocasiones se pudieron probar las actividades delictivas reprochadas a las ONG o que existieran lazos entre las ONG y los traficantes ${ }^{80}$.

Junto a ello, con el aliento de la Comisión Europea ${ }^{81}$, en el verano de 2017 Italia lanzó un código de conducta para las ONG dedicadas a operaciones de salvamento ${ }^{82}$ que requiere a estas entidades, entre otras cosas, que se abstengan de penetrar en las aguas territoriales libias, salvo en situaciones de grave e inminente peligro, y seguir las indicaciones de las autoridades competentes de los Estados en esta materia de salvamento marítimo ${ }^{83}$.

Esa especial relación con el Estado libio por parte de Italia, que le llevó a prohibir a los buques de salvamento de las ONG la penetración en aguas libias, deriva de varios acuerdos bilaterales, en particular sobre la base del Acuerdo de Amistad, Asociación y Cooperación de agosto de 2008 y el Memorándum de Entendimiento de 2 de febrero $2017^{84}$. En este último, Italia y Libia acordaron cooperar en el sector del desarrollo para reforzar la seguridad fronteriza y combatir la inmigración irregular, la trata de seres humanos y el contrabando ${ }^{85}$. De acuerdo con las disposiciones de este último instrumento, Italia se comprometía, entre otras cosas, a financiar proyectos de desarrollo en

80 Véase, a este respecto, el dictamen de la Comisión de Defensa del Senado Italiano de 16 de mayo de 2017: "Documento conclusivo approvato dalla commissione sull'indagine conoscitiva sul contributo dei militari italiani al controllo dei flussi migratori nel Mediterraneo e l'impatto delle attivita' delle organizzazioni non governative (doc. xvii, n. 9)». Disponible en: https://bit.ly/2BKacG6.

81 European Commission, Action Plan on measures to support Italy, reduce pressure along the Central Mediterranean route and increase solidarity, Brussels 4 July 2017, Doc. SEC (2017) 339.

82 Sobre el código de conducta véase Cusumano (2019: 106-114) y Smith (2017: 45-46).

83 En este sentido, véase Gombeer y Fink (2018: 4-8). Puede encontrarse el código de conducta en: https://bit.ly/2oi9NYx. La relatora especial sobre ejecuciones extrajudiciales, sumarias o arbitrarias en la Oficina del Alto Comisionado de las Naciones Unidas para los Derechos Humanos, Agnès Callamard, advirtió al poco tiempo de conocerse el código de conducta que limitaría la capacidad de salvar vidas de los buques de salvamento de las ONG. Véase OHCHR, «Italy-EU Search and Rescue Code Could Increase Mediterranean Deaths, UN experts warn», 15 August 2017. Disponible en: https://bit.ly/2MN2NfN.

84 Véase, a este respecto, Doc. 11471/18, EEAS, Strategic Review on EUNAVFOR MED Operation Sophia..., op. cit., p. 19. Otros Estados miembros de la UE han adoptado tratados bilaterales de cooperación con Libia en el marco de la lucha contra la inmigración ilegal, véase en este sentido: ibid.

85 Véase el memorándum en: https://bit.ly/34ce92P. 
las regiones libias más afectadas por la inmigración ilegal y a aportar ayuda técnica y tecnológica a las autoridades libias responsables de la lucha contra ese fenómeno ${ }^{86}$.

$\mathrm{El}$ acoso a las ONG que hemos señalado por parte de Italia se ha ido incrementando a partir del verano de 2017 en que se publicó el código de conducta. Así, las autoridades italianas se han incautado algunos buques de las ONG y han puesto en marcha investigaciones penales y administrativas para hacer frente a las acciones de esos buques al considerar que exceden de sus actividades de rescate en el $\mathrm{mar}^{87}$; situación que también se ha reproducido en otros Estados miembros de la UE, como España, Grecia o Malta ${ }^{88}$. En mi opinión, las medidas que están adoptando estos Estados miembros de la UE podrían ir contra lo que establece, aunque no tenga valor coercitivo, la directriz del Comité de Seguridad Marítima de la Organización Marítima Internacional (OMI) según la cual: «6.3 Ningún buque debe sufrir demoras indebidas, carga financiera u otras dificultades conexas tras haber prestado auxilio a personas en el mar; por consiguiente, los Estados ribereños deben liberar los buques tan pronto como sea posible» ${ }^{89}$, aunque por supuesto esta regla debe aplicarse en conjunción con otras normas y principios jurídicos.

Para acabar esta sección debemos advertir que en las últimas semanas asistimos a una especie de desafío por parte de algunas ONG hacia Italia, pues sus buques están entrando en los puertos italianos para desembarcar a las personas que han rescatado en el mar sin autorización de las autoridades de ese Estado ${ }^{90}$.

\section{EL PAPEL DE LA ACTUACIÓN DE LAS FUERZAS DE GUARDACOSTA LIBIAS EN LA HIBERNACIÓN DE LA OPERACIÓN NAVAL DE LA UNIÓN EUROPEA}

Debido a la ausencia de autorizaciones del CSNU para operar en el mar territorial o en el territorio terrestre de Libia, se hace imperativo para Sophia

86 Véase el art. 1 del memorándum de 2017.

87 A este respecto, véas: European Union Agency for Fundamental Rights, «Fundamental rights considerations: NGO ships involved in search and rescue in the Mediterranean and criminal investigations - 2018», disponible en: https://bit.ly/32NdFQg. Ibid.

9 Resolución 167 (78), Directrices respecto de la actuación con las personas rescatadas en el mar, MSC 78/26/Add.2 ANEXO 34, parr. 5.1.2.

90 Véase, por ejemplo, «Sea-Watch migrant rescue boat defies Salvini, enters Italian waters». Disponible en: https://bit.ly/31Pcj6a. 
contar con el consentimiento del Estado ribereño si se quiere imponer el orden en esos espacios. No obstante, en el caso presente, la situación política que ha atravesado Libia en los últimos años y el rechazo a nuevas intervenciones extranjeras dificultan enormemente que se forme un consentimiento favorable y que se manifieste el mismo en la esfera internacional ${ }^{11}$.

A este respecto, la firma del acuerdo de 17 de diciembre de 2015 de Sjirat, Marruecos, para formar un Gobierno de consenso nacional, constituyó quizá un avance, aunque, desde luego, no sirvió para reconstruir la autoridad estatal en todo el territorio de Libia, como los acontecimientos de las últimas semanas han puesto, si hiciera falta, sobradamente de manifiesto. En efecto, como de todos es sabido, la inestabilidad política reciente impidió celebrar unas elecciones generales a finales de 2018 y movió al enviado especial de las Naciones Unidas para Libia a convocar una conferencia nacional que debería haber tenido lugar los días 16 y 17 de abril de 2019 con el fin de lograr la reconciliación nacional entre las diversas facciones. Desgraciadamente, esa conferencia nacional a la postre fue suspendida, ya que, a principios de abril de 2019, el general Hafter, que había creado el denominado Ejército Nacional de Libia, lanzó una ofensiva militar tendente a controlar Trípoli, sin que se sepa aún qué derrotero tomarán los acontecimientos en este país clave para el futuro y el éxito de la operación Sophia ${ }^{92}$.

En cualquier caso, el 20 de junio de 2016, en virtud de su Resolución 2016/993 ${ }^{93}$, el Consejo de la UE encargó a la dotación de la operación Sophia la formación y capacitación de la Guardia Costera y la Armada libias para la realización de tareas policiales en el mar, en especial para luchar contra el tráfico ilícito y la trata de personas. Ello es coherente con la línea marcada en el plan de acción en el marco de la Estrategia de Seguridad Marítima de

91 Sobre la oposición de Libia a cualquier intervención externa, Gaub (2014: 51). Véase, asimismo, Hermoso (2016: 176) o Doc. 11471/18, EEAS, Strategic Review on EUNAVFOR MED Operation Sophia..., op. cit., p. 38.

92 Sobre la situación actual y sus precedentes, véase Doc. 11471/18, EEAS, Strategic Review on EUNAVFOR MED Operation Sophia..., op. cit., pp. 4-5 y 9-13 o Fuente Cobo (2017b). Véase, asimismo, sobre la evolución de los acontecimientos en Libia: Departamento de Seguridad Nacional, «Situación en Libia, 17.04.2019». Disponible en: https://bit.ly/2JnFpDl. Sobre la situación actual y sus precedentes, véase asimismo Doc. 11471/18, EEAS, Strategic Review on EUNAVFOR MED Operation Sophia..., op. cit., pp. 4-5 y 9-13 o Fuente Cobo (2017a).

93 Decisión (PESC) 2016/993 del Consejo, de 20 de junio de 2016, por la que se modifica la Decisión (PESC) 2015/778 relativa a una operación militar de la Unión Europea en el Mediterráneo central meridional (operación EUNAVFOR MED SOPHIA), (DO L 162, de 21 de junio de 2016, p. 18). 
la Unión Europea de diciembre de 2014, con el que se trata de abordar el contrabando de migrantes y la trata de seres humanos de manera más efectiva en el ámbito marítimo, mediante el desarrollo de programas de creación de capacidad en materia de seguridad con terceros países, centrándose en los países y rutas prioritarios ${ }^{94}$.

De esta manera, en el verano de 2017 las autoridades libias declararon el establecimiento de una zona SAR, aunque posteriormente fue retirada y reemplazada el 14 de diciembre de 2017. El establecimiento de la zona SAR libia, en la que no deberían operar buques extranjeros, cuenta con el apoyo operativo del Centro Nacional de Coordinación del Rescate Marítimo de la Guardia Costera de Italia y con ayuda financiera de la Comisión Europea ${ }^{95}$.

Así, poco a poco, las autoridades militares libias, con la formación del personal de la operación Sophia y de Italia, se fueron haciendo cargo de la lucha contra los traficantes de migrantes y de las labores de rescate y salvamento, primero en sus aguas, aunque luego, de forma creciente, en aguas internacionales. De esta manera, ya en 2017, lograron interceptar o rescatar alrededor de 15000 personas — cifras que se volvieron a alcanzar en $2018^{96}$ - que han sido sistemáticamente desembarcadas en puertos libios.

Sin embargo, las acusaciones de violación grave de los derechos humanos de los migrantes por parte del personal de la Guardia Costera de Libia durante las operaciones de rescate, o posteriormente en los centros de retención en territorio libio, han sido numerosas y lacerantes ${ }^{97}$. La situación parece llegar a

94 Véase el punto 1.3.2 del plan de acción en el marco de la Estrategia de Seguridad Marítima de la Unión Europea: Council of the European Union, European Union Maritime Security Strategy (EUMSS) - Action Plan, adopted on 16 December 2014 by the General Affairs Council.

95 United Nations Support Mission in Libya, Office of the High Commissioner for Human Rights, «Desperate and dangerous: Report on the Human Rights situation of migrants and refugees in Libya», 20 December 2018, p. 17. Véase, asimismo, Doc. 11471/18, EEAS, Strategic Review on EUNAVFOR MED Operation Sophia..., $o p$. cit., p. 15. Véase también la pregunta en el Parlamento Europeo de Sabine Lösing sobre la zona SAR de Libia el 3 de julio de 2018 y la respuesta del comisario Avramopoulos en https://bit.ly/2MNoZX5.

96 Comisión Europea, Comunicación de la Comisión al Parlamento Europeo, al Consejo Europeo y al Consejo, Informe de situación sobre la aplicación de la Agenda Europea de Migración, Bruselas, 6 de marzo de 2019, Doc. COM(2019) 126 final, p. 3. Sobre la contribución de Sophia y de Italia al aumento de la capacidad policial de las autoridades libias, véase también Poncela Sacho (2019: 11-12).

97 Sobre este punto véase: «Desperate and dangerous: Report on the Human Rights situation of migrants and refugees in Libya»..., op. cit., pp. 25-54. 
tal límite que, incluso, el 8 de mayo de 2018 diecisiete supervivientes de un incidente de salvamento marítimo llevado a cabo por los guardacostas libios el 6 de noviembre de 2017 presentaron una demanda contra Italia en el Tribunal Europeo de los Derechos Humanos invocando su responsabilidad por muertes en el mar y por permitir el desembarco de migrantes en Libia, donde corren riesgo de sufrir graves violaciones de derechos humanos ${ }^{98}$. Recuérdese que el Tribunal Europeo de Derechos Humanos, por ejemplo en el asunto Hirsi Jamaa y otros contra Italia, ya condenó a este Estado por violaciones del art. 3 del Convenio Europeo de Derechos Humanos debido a que unos guardacostas italianos, en virtud de un acuerdo bilateral entre ambos países, habían devuelto unos doscientos migrantes interceptados en alta mar a Libia, donde corrían serio riesgo de sufrir importantes violaciones en sus derechos fundamentales ${ }^{9}$.

En mi opinión, como se puede apreciar, a causa tanto de la situación política en Libia en estos momentos, técnicamente en una situación muy parecida a una guerra civil, como de las manifiestas violaciones de los derechos humanos que se están produciendo por parte de los guardacostas libios, la UE debe, cuando menos, reforzar en el marco de la operación Sophia las garantías precisas a la hora de prestar la formación a las fuerzas de seguridad libias para que respeten los derechos humanos de los migrantes, o reforzar las competencias de la operación EUBAM Libia para que ese control y esa formación se presten a través de esta operación.

\section{CONCLUSIONES}

A lo largo de estas páginas se ha evidenciado que si bien durante estos años los buques de Sophia no han acabado con el modelo de negocio de tráfico de migrantes en el Mediterráneo central, su presencia y actividad en alta mar ha dificultado la labor de los criminales en ese espacio marítimo y contri-

98 Global Legal Action Network, «Legal Action Against Italy over its Coordination of Libyan Coast Guard Pull-backs Resulting in Migrant Deaths and Abuse», May 2018. Disponible en: https://bit.ly/2WdRzDW.

99 Tribunal Europeo de Derechos Humanos, Hirsi Jamaa y otros contra Italia [GS], n. ${ }^{\circ}$ 27765/09, 23 de febrero de 2012. Sobre este caso véase Pijnenburg (2018: 396426). Asimismo, sobre la responsabilidad internacional de Italia por las violaciones de los derechos humanos de los migrantes a cargo de militares y policías libios, véase Pascale (2019: 35-58). El profesor Pascale concluye que Italia es responsable internacionalmente por la ayuda y asistencia que presta a Libia en su gestión de la crisis migratoria. 
buido a aumentar la seguridad general en la zona, y a ello hay que sumar las importantes consecuciones de los buques de la UE en cuanto a salvamento y rescate de personas en las aguas del Mare Nostrum.

Por el contrario, la ayuda de la UE y de Italia a la formación de las fuerzas de seguridad de Libia para que ejerzan el control marítimo en sus aguas están siendo duramente criticadas a causa de las presuntas violaciones de los derechos humanos de los migrantes que las fuerzas de seguridad libias habrían cometido.

Sin embargo, quizá, el elemento más determinante para que la valoración global de la operación Sophia resulte negativa venga constituida por su parálisis actual, que se explica por la ausencia de consenso político en torno a las reglas de desembarco y distribución posterior de migrantes.

En este sentido da la impresión que hubiera sido mejor programar al inicio no una operación militar tan ambiciosa como Sophia en su origen, sino una operación de gestión de crisis mixta, militar y civil, suficientemente robusta en el exterior, buscando los debidos acuerdos con las autoridades libias; rumbo al que parece que se había ido dirigiendo la operación Sophia con el transcurso del tiempo. Aunque, por supuesto, ante el éxito de Atalanta era lógico optar por repetir la fórmula sin que, además, se pudiera saber a priori que ni Libia ni el CSNU iban a autorizar la intervención en espacios bajo la soberanía de ese Estado.

Por ejemplo, el Consejo de la UE, en sus conclusiones de 2016 sobre la aplicación de la Estrategia Global de la UE en materia de seguridad y defensa, ya advirtió que, entre los diversos tipos de operaciones civiles y militares que se podrían lanzar en el marco de la PCSD, se encontraban aquellas destinadas a la creación de capacidades civiles y de reforma del sector de la seguridad (supervisión, tutoría y asesoramiento, formación), entre otras cosas en relación con la Policía, la gestión de fronteras, etc. ${ }^{100}$.

Debido a que parte de las funciones que acabamos de señalar han sido ya atribuidas a la operación EUBAM Libia con el transcurrir del tiempo, quizá la mejor solución en la encrucijada que nos encontramos ahora sea reforzar el mandato de esta operación y, si se resuelve el problema de la falta de solida-

100 Council conclusions on implementing the EU Global Strategy in the area of Security and Defence-Council conclusions (14 November 2016), Brussels, 14 November 2016 (OR. en) 14149/16. Andrea Cocchini propone, en esta misma línea, transformar la operación Sophia «en una operación mixta de gestión de crisis que, gracias a una correcta aplicación del principio de la responsabilidad de proteger, garantice el mantenimiento de la paz y la seguridad internacionales perturbadas por las actividades ilícitas de los traficantes». Véase, al respecto, Cocchini (2018: 18). 
ridad en cuanto al desembarco y distribución posterior de migrantes, volver a lanzar una operación naval que pudiera reforzar la seguridad global en el Mediterráneo central, ya sin la pretensión, que hoy parece utópica, de actuar en aguas y en el territorio terrestre de Libia.

En este contexto, asimismo, habría que estudiar y resolver el problema de las operaciones de salvamento y la complementariedad de los actores estatales y comunitarios con las ONG.

En definitiva, en honor de la verdad, estimo que la valoración global negativa de Sophia no debe ser tenida por un fracaso de la operación en sí misma, sino más bien como un revés para la PCSD, pues han contribuido a su hibernación más las circunstancias coyunturales externas a Sophia que su falta de consecuciones. Piénsese que para adoptar decisiones en el ámbito de la PCSD se tiene que contar con la unanimidad de los Estados miembros, y en el caso concreto que examinamos, Italia está bloqueando el futuro de la operación; no sin razón, quizá, en un contexto más general de reparto de responsabilidades en materia migratoria en la UE, en el que ha faltado solidaridad entre los Estados miembros. Junto a ello, la parálisis actual de Sophia se explica también por la ausencia de autorización a la operación para operar en aguas territoriales libias, y luego en el territorio terrestre de ese Estado, por parte del CSNU y del Estado libio.

Con esos trazos, la imagen final del cuadro es la de una operación Sophia atada de manos, a la vez por imperativos internos, del funcionamiento de la Unión, como por imperativos externos, de política internacional asociada al uso de la fuerza en la sociedad contemporánea.

Sea como fuere, es indudable que el devenir de la operación Sophia pone una vez más de manifiesto los límites de la PCSD. Difícilmente la Unión podrá llegar a ser el actor influyente de referencia en la escena mundial al que se aspira sin una solidaridad entre los Estados miembros y sin dotarla de las competencias necesarias para ello.

Aún más preocupante resulta el hecho de que, con el apoyo de la UE a Libia en su lucha contra el tráfico de migrantes, y las posibles violaciones de los derechos humanos que parece que se están cometiendo, la imagen de continente pionero y líder en este ámbito se está deteriorando seriamente ${ }^{101}$.

101 Véase, en este sentido, Council of Europe, Committee on Migration, Refugees and Displaced Persons, International obligations of Council of Europe member States: to protect life at sea. Report., Doc. 14586, 26 June 2018. 


\section{Bibliografía}

Acosta Sánchez, M. A. (2018). Sobre el ámbito competencial de las operaciones de paz: el enfoque integral de la operación militar Sophia de la UE ante la crisis migratoria. Revista del Instituto Español de Estudios Estratégicos, 12, 15-48.

Arteaga Martín, F. y González Enríquez, C. (2015). La respuesta militar a la crisis migratoria del Mediterráneo. Real Instituto Elcano, ARI, 40.

Butler, G. y Ratcovich, M. (2016). Operation Sophia in Uncharted Waters: European and International Law Challenges for the EU Naval Mission in the Mediterranean Sea. Nordic Journal of International Law, 85 (3), 235-259. Disponible en: https://doi.org/10.1163/15718107-08503003.

Cocchini, A. (2018). Tráfico ilícito de migrantes y operación Sophia: ¿podría aplicarse de nuevo la responsabilidad de proteger en Libia? Revista Electrónica de Estudios Internacionales, 35. Disponible en: https://doi.org/10.17103/reei.35.08.

Cusumano, E. (2019). Straightjacketing migrant rescuers? The code of conduct on maritime NGOs. Mediterranean Politics, 24 (1), 106-114. Disponible en: https://doi.org/10.1080/13629395.2017.1381400.

De Castro Ruano, J. L. y Borrajo Valiña, D. (2019). El futuro de la seguridad y la defensa en la UE post-Brexit: el salto a la integración. Cuadernos Europeos de Deusto, 60, 187-217. Disponible en: https://doi.org/10.18543/ced-602019pp187-217.

Esteve, F. (2015). El rescate como nueva función europea en la vigilancia del Mediterráneo. Revista CIDOB d'Afers Internacionals, 111, 153-172.

Faleg, G. y Blockmans, S. (2015). EU Naval Force EUNAVFOR MED sets sail in troubled waters. Centre for European Policy Studies Commentary, 26 June 2015. Disponible en: https://bit.ly/32vX5UY.

Fuente Cobo, I. (2017a). Las migraciones en el espacio euromediterráneo: causas y perspectivas de futuro. Documento de análisis 53/2017. Instituto Español de Estudios Estratégicos, 368-387. Disponible en: https://bit.ly/2hgyJf4.

Fuente Cobo, I. (2017b). Libia, la guerra del General Jalifa Haftar. Documento de análisis 70/2017. Instituto Español de Estudios Estratégicos, 280-296. Disponible en: https://bit.ly/2hgyJf4.

Gaub, F. (2014). The EU and Libya and the Art of the Possible. The International Spectator: Italian Journal of International Affairs, 49 (3), 40-53. Disponible en: https://doi.org/10.1080/03932729.2014.937093.

Gombeer, K. y Fink, M. (2018). Non-Governmental Organisations and Search and Rescue at Sea. Maritime Safety and Security Law Journal, 4, 1-25. Disponible en: https://bit.ly/31vM6JJ.

Gowlland-Debbas, V. (2007). The link between Security and International Protection of Refugees and Migrants. Mondialisation, Migration et Droits de L'homme, 2, 281-317. 
Hermoso, E. (2016). Lecciones aprendidas por la Unión Europea aplicables en Libia. Revista de Estudios en Seguridad Internacional, 2 (2), 171-204. Disponible en: https://doi.org/10.18847/1.4.8.

Himmrich, J. (2019). Beyond operation Sophia What role for the military in migration policy? Dahrendorf Forum Policy Brief, 4 march 2019. Disponible en: https://bit.ly/327EDly.

Koutrakos, P. (2013). The EU Common Security and Defence Policy. Oxford: Oxford University Press. Disponible en: https://doi.org/10.1093/acprof:oso/9780199692729.001.0001.

Nováky, N. (2018). The road to Sophia: Explaining the EU's naval operation in the Mediterranean. European View, 17 (2), 197-209. Disponible en: https://doi. org/10.1177/1781685818810359.

Papanicolopulu, I. (2016). The duty to rescue at sea, in peacetime and in war: A general Overview. International Review of the Red Cross, 98 (2), 491-514. Disponible en: https://doi.org/10.1017/S1816383117000406.

Pascale, G. (2019). Is Italy internationally responsible for the gross human rights violations against migrants in Libya? Questions of International Law, 56, 35-58.

Pijnenburg, A. (2018). From Italian Pushbacks to Libyan Pullbacks: Is Hirsi 2.0 in the Making in Strasbourg? European Journal of Migration and Law, 20 (4), 396-426. Disponible en: https://doi.org/10.1163/15718166-12340036.

Poncela Sacho, A. (2019). EUNAVFOR MED Operación SOPHIA: un instrumento de la Política Exterior y de Seguridad Común de la Unión Europea. Documento de Opinión IEEE 05/2019. Instituto Español de Estudios Estratégicos, 13, 359-373. Disponible en: https://bit.ly/2J9f1gg.

Rasche, L. (2018). In troubled waters: What does the future hold for Operation Sophia? Jacques Delors Institute, Berlin. Policy Brief, 1-7. 14 December 2018. Disponible en: https://bit.ly/35T75d1.

Smith, A. (2017). Uncertainty, Alert and Distress: The Precarious Position of NGO Search and Rescue Operations in the Central Mediterranean. Paix et Securité Internationales, 5, 29-70. Disponible en: https://doi.org/10.25267/Paix_secur_ int.2017.i5.02.

Steinhilper, E. y Gruijters, R. J. (2018). A Contested Crisis: Policy Narratives and Empirical Evidence on Border Deaths in the Mediterranean. Sociology, 52 (3), 515-533. Disponible en: https://doi.org/10.1177/0038038518759248.

Vacas Fernández, F. (2016). The European operations in the Mediterranean Sea to deal with migration as a symptom: From the Italian operation Mare Nostrum to Frontex operations Triton and Posseidon, EUNAVFOR-MED and NATO's assistance in the Aegean Sea. Spanish Yearbook of International Law, 20, 93-117. Disponible en: https://doi.org/10.17103/sybil.20.07. 